\title{
Intuition in Organizations: Implications for Strategic Management
}

\author{
Gerard P. Hodgkinson, Eugene Sadler-Smith, Lisa A. Burke, \\ Guy Claxton and Paul R. Sparrow
}

Recent advances in social cognitive neuroscience and related fields have rejuvenated scholarly research into intuition. This article considers the implications of these developments for understanding managerial and organizational decision making. Over the past two decades, researchers have made considerable progress in distinguishing intuition from closely-related constructs such as instinct and insight and the interplay between these non-conscious forms of cognition and explicit reasoning processes is now better understood. In the wake of significant theoretical and methodological convergence centred on dual-process theories of reasoning, judgment and social cognition, supported by functional magnetic resonance imaging (fMRI) studies, several of the foundational assumptions underpinning classic theories and frameworks in strategic management and entrepreneurship research are being called into question. Old models based on a simplistic left brain/right brain dichotomy are giving way to more sophisticated conceptions, in which intuitive and analytical approaches to decision making are underpinned by complex neuropsychological systems. In the light of these advances, the authors offer their reflections on what this all means for the assessment, development and management of intuition in the workplace.

(c) 2009 Elsevier Ltd. All rights reserved.

\section{Introduction}

Until comparatively recently, only the bravest and most farsighted of individuals would acknowledge the utility of intuition in business management. For example, several decades ago, one of the founders of Raychem claimed that the decisions he regretted were the ones not based on intuition. At Genentech, one of the world's leading biotechnology companies, CEO Arthur Levinson has said that "as a manager it often comes down to intuition. Is it going to work or not?" Indeed, Genentech 
is a company in which scientists are encouraged to act on promising leads, follow their intuition and test hypotheses - a recipe that enables "great science" rather than mere "formula". The co-founder of Sony, Akio Moriata, and the driving force behind one of the entertainment innovations of the 20th century, the Sony Walkman, stated that "creativity requires something more than the processing of information. It requires human thought, spontaneous intuition and a lot of courage". ${ }^{1}$ Notwithstanding these and many other examples of the power of intuition in judgment and strategic decision making, managers in general (particularly those at lower levels) are often averse to admitting to its usefulness. Perhaps one reason for this reluctance is because, historically, intuition has been viewed as a vague and irrational notion; however, scientific progress over the past two decades has: (1) clarified the nature of intuition, bringing much-needed conceptual precision to bear in order to differentiate it from a number of related concepts; (2) identified the psychological processes and neurobiological mechanisms underpinning its operation and use; (3) illuminated the circumstances in which it is deployed effectively, and; (4) proposed relatively robust methods by which it may be assessed and developed. Reviewing these advances in the context of the dramatic changes that have occurred in the modern workplace, in this article we argue that informed intuition is as essential to the competence portfolio of hard-pressed decision makers as many of the analytical skills that feature in contemporary business school curricula. ${ }^{2}$

\section{The information processing challenges of the modern workplace}

Complexity and dynamism in hypercompetitive business environments allied to new organizational structures and work practices are placing unprecedented demands on the information processing capacities of individuals and groups. These problems are further compounded by technological advances that have resulted in a surfeit of information that managers are required to sort, interpret, prioritise and act on. ${ }^{3}$ Given the nature of these demands and the limited timeframes within which decisions are typically made, it is of little surprise that managers' information processing capacities are often exceeded and that they behave in ways that aspire to be rational but are so only within cognitively-circumscribed limits. The conventional model of bounded rationality espoused by Herbert Simon, resonating with the earlier writings of Chester Barnard in the 1930s on the role of non-logical processes in management, not only acknowledged the computational limits of decision makers, but also acceded to a potential role for non-cognitive processes, such as affect, and, in particular, intuition. ${ }^{4}$

Notwithstanding their profundity and impact over several decades, the insights offered by Simon and Barnard do not accord with current understanding of the interplay of intuition and analysis in organizational decision processes, informed by the latest advances in cognitive and social psychology and the emerging field of social cognitive neuroscience. Reflecting the fact that intuition operates at the nexus of thinking and feeling, contemporary dual-process theories of judgment and decision making are uniquely placed to account for the ways in which strategists are able to meet the information processing demands of the modern workplace, which are daunting to say the least. Against this backdrop, the notion of strategic competence, defined as the ability of organization members to acquire, store, recall, interpret and act on information that is relevant to the survival and wellbeing of the organization, is vitally important. ${ }^{5}$

In our view, intuitive judgment is an indispensable component of strategic competence. Accordingly, improved knowledge of the factors that promote the successful deployment of intuition might be used not only to select, train, appraise and reward individuals, but also to configure strategy teams in ways that leverage the capability of organizations to become more cognitively skilled, thus enhancing their capacity for learning and renewal. To this end, in later sections of this article we suggest that the development of managers' intuition in the workplace can be leveraged by developing individuals' expertise, self-awareness and reflexivity. Furthermore, as strategic competence is a collective activity, we consider the implications of our analysis for managing and leading teams, such that a requisite blend of individual cognitive competencies (both intuitive and analytical) and the development of shared understandings of intuitions (which are inherently subjective and experiential) might be achieved. We begin by providing a background review of current knowledge of intuition from the 
fields of cognitive and social psychology, social cognitive neuroscience and decision research before offering a number of arguments concerning the strategic applications of intuition.

\section{What is intuition?}

In recent decades, the possibility that much of human thought, including a number of higher-level cognitive operations, is non-conscious has become a centrally important precept of modern cognitive science. ${ }^{6}$ Reasoning is seen no longer as an exclusively conscious or deliberative process. Rather, consciousness, as well as being, figuratively speaking, the "workshop" of the mind, is also the "control panel" upon which signals from the "interior" appear to offer potential guidance for individual judgment and decision making. One such signal, intuition, is an important faculty of the so-called "intelligent-unconscious". It is a judgment for a given course of action that comes to mind with an aura or conviction of rightness or plausibility, but without clearly articulated reasons or justifications - essentially "knowing" but without knowing why.

Reasoning is seen no longer as an exclusively conscious or deliberative

\section{process}

Intuition is not the same as instinct; nor is it equivalent to insight. Unfortunately, however, a number of authors and managers conflate these concepts. ${ }^{8}$ Although popular management writers frequently adopt the terms "business instinct" and "intuitive insight", it is important to note that from a psychological standpoint, instinct pertains merely to hardwired, autonomous reflex actions, for example a "knee-jerk", or the behaviour patterns of certain animals (such as the homing instinct in birds). Insight, on the other hand, is a sudden and unexpected solution to a problem, arrived at after an impasse has been reached and an incubation period has elapsed. The point at which the solution occurs is sometimes referred to as a "eureka" moment and is a prominent feature of many tales of important scientific discoveries, including those of Archimedes, Newton, Kekule and Poincaré. An incubation period is often necessary for insight to occur because it enables non-conscious processes to operate more freely by relaxing constraints imposed by rational analysis. An intuition of a solution may presage the insightful moment, in other words: intuitions are intimations of insights experienced as "feeling of knowing" or "tip of the tongue" phenomena. Such intimations have been reported in the accounts of a number of Nobel Prize-winning scientists, who interpreted them as signposts on the route to major scientific discoveries. ${ }^{9}$ The neural process of "spreading activation" among nodes in long-term memory (again, operating beneath the level of conscious awareness) enables the production of associations and novel and unexpected connections among concepts, and this is one of the hallmarks of creativity. ${ }^{10}$ The subtle distinctions between insight and intuition are beginning to be mapped by cognitive neuroscientists using functional magnetic resonance imaging (fMRI) techniques. For example, one study identified the anterior superior temporal gyrus (aSTG) region of the right hemisphere of the brain as a location of the connections that occur at the moment of insight. Other, more recent, work has identified the orbito-frontal cortex (OFC) and the amygdala to be activated in intuitive judgments, both of which are regions also involved in emotionally-driven decisions. ${ }^{11}$ It is important to note that neither insight nor intuition occur in a cognitive vacuum or in an "unprepared mind"; rather, learning and experience constitute the substances on which such associative processes operate. Insight, the ability to see into and articulate the structure of a problem, is thus as important as intuition in the repertoire of cognitively-skilled strategists. The challenge for managers, leaders and organizations is to create the enabling conditions for both of these processes to flourish.

For many years, intuition research was dogged by problems of weak conceptualization, manifested in multiple and sometimes conflicting definitions, emanating from fields as disparate as 
Jungian psychoanalysis and cognitive psychology. These definitional issues - to a certain extent manifestations of healthy disparities - can never be totally resolved; for example a behavioural decision researcher within the heuristics and biases tradition is unlikely to define intuition in the same way as a social cognitive neuroscientist. However, in management at least, there appears to be a growing consensus that intuition comprises the following:

(1) a capacity for attaining direct knowledge or understanding without the apparent intrusion of rational thought or logical inference;

(2) neither the opposite of rationality, nor a random process of guessing, intuition corresponds to thoughts, conclusions and choices produced largely or in part through non-conscious mental processes;

(3) affectively charged judgments that arise through rapid, non-conscious and holistic associations. $^{12}$

Insights and intuitions are related only in so far as an intuition may precede an insight as a "feeling of knowing", or an intimation of a potential problem solution. However, not all intuitions become insights; many remain as unconfirmed hypotheses or judgments, while some become the subject of empirical verification or refutation. ${ }^{13}$ Moreover, the affective charge that is an outcome of the intuitive process is distinct from emotions per se.

\section{Insights from dual-process formulations}

Cognitive scientists are increasingly in agreement that humans process information by means of two systems, which may be grouped together under the umbrella notion of System 1 and System 2 information processing architecture. ${ }^{14}$ In evolutionary terms, System 1 processes are older; they operate largely beyond conscious awareness on an automatic basis. As such, they require minimal cognitive resources. System 2 processes, in contrast, emerged comparatively recently in Homo sapiens' evolution and require effortful attention, thus placing a premium on the brain's limited processing capacities. As noted earlier, dual-process accounts of judgment and decision making, in our view, offer a compelling psychological explanation for the interplay of intuition and analysis in managerial thought and action. Of the multiplicity of dual-process theories within the cognitive and social psychology literatures, Cognitive-Experiential Self-Theory (CEST), developed by the social psychologist Seymour Epstein and his colleagues, is the most apposite for basing our discussion of intuition in the strategic management process. ${ }^{15}$ As shown in Exhibit 1, CEST is a global theory of personality that integrates the cognitive and the psychodynamic unconscious, based on two interactive modes of information processing.

Dual-process theories such as CEST provide a broad conceptual framework within which the construct of intuition can be located conveniently alongside more conventional approaches. Such theories do not seek to offer explanations of the underlying mechanisms that enable certain individuals to form intuitive judgments and incorporate them within their wider decision-making repertoire. Fortunately, however, recent advances in two seemingly unrelated fields of study, cognitive/social cognitive neuroscience and naturalistic decision making (NDM), provide key insights in this regard.

\section{Insights from cognitive and social cognitive neuroscience}

Recent advances in cognitive and social cognitive neuroscience have displaced the notion that individuals are marked by an overwhelming preference for analytical or intuitive approaches to information processing, a tendency historically attributed to gross hemispheric specialization. ${ }^{17}$ Known as the lateralisation hypothesis, this outmoded view, still adhered to by a number of contemporary writers on managerial decision making, was first popularised in the 1970s by Henry Mintzberg. ${ }^{18}$ Mintzberg and other management writers at that time used contemporary insights of neuropsychology to powerful effect, arguing that formal business planning relied on the left hemisphere's sequential-logical processes, whereas the less formal, intuitive aspects of management were accomplished by the right hemisphere of the cerebral cortex, as depicted in Exhibit 2. 


\section{Exhibit 1: System 1/System 2 Processes and Cognitive Experiential Self- Theory}

Generic descriptions and examples

System 1

System 2

Sources $^{16}$

Associative; holistic; automatic; undemanding of cognitive capacity; relatively fast operation; acquisition by biology, exposure and personal experience
Rule-based; analytic; controlled; demanding of cognitive capacity; relatively slow operation; acquisition by cultural and formal tuition
Evans (2003, 2008)

Stanovich (1999)

Stanovich and West (2000)

Epstein's cognitive experiential self-theory
Experiential system
Rational system
Sources $^{16}$

Holistic; automatic, effortless; affective; associationistic; mediated by 'vibes' from past events; concrete images, metaphors, narratives; more rapid, immediate action; slower more resistant to change; changes with repetitive/intense experience
Analytic; intentional, effortful; logical; mediated by conscious appraisal of events; abstract symbols, words, numbers; slower, delayed action; changes more rapidly; changes with strength of argument, new evidence
Epstein (1994, 2008)

Epstein et al (1996)

\section{Exhibit 2}

Hemispheric Specialization and Human Information Processing in Management Decision Making, based on the now outmoded lateralization of function hypothesis. (Source: W. Taggart and D. Robey, 1981, Minds and Managers: On the dual nature of human information processing and management. Academy of Management Review, 6(2), p. 187-195). (C)1981 by The Academy of Management. Reproduced by kind permission of the publisher.
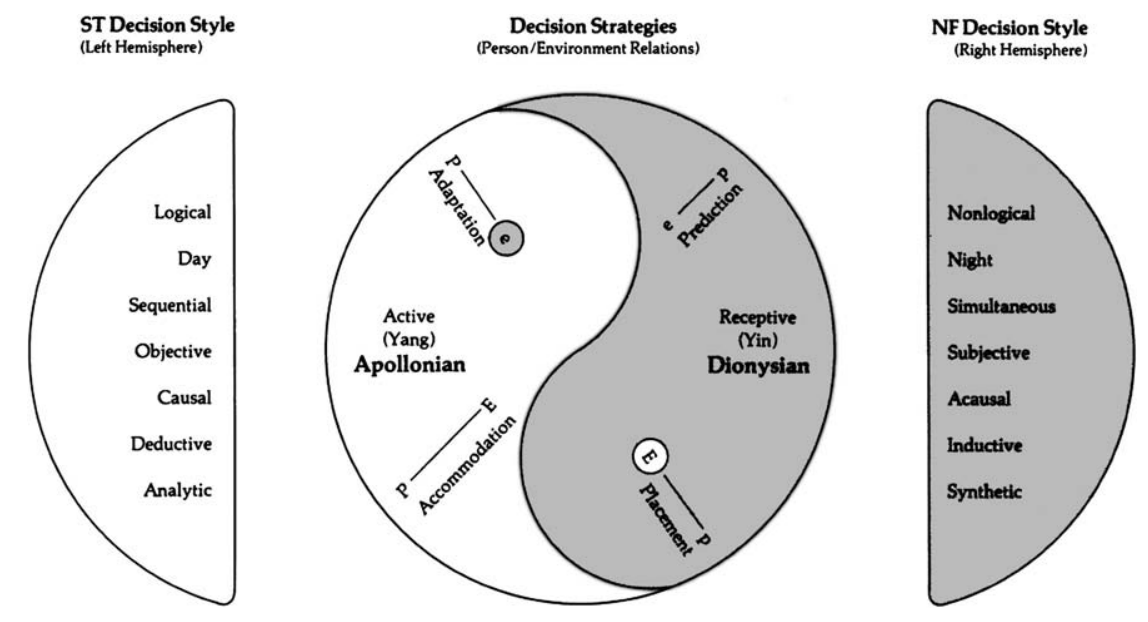
Reflecting various advances in cognitive neuroscience that have occurred over the years, some writers in management have suggested more recently that the notion of hemispheric specialization is now better thought of as a convenient metaphor for two modes of processing, rather than a literal representation of the neural substrates of intuition and analysis. ${ }^{19}$ However, in the light of the very latest developments in social cognitive neuroscience and related fields (see Exhibit 3), in our view talk of gross left brain/right brain differences in information processing is perhaps best avoided altogether. $^{20}$

One other body of recent evidence from the field of cognitive neuroscience is also worthy of mention. As discussed in Exhibit 4, in a series of seminal studies, the clinical neurologist Antonio Damasio and his colleagues compared the performance of normal participants and patients with damage to the ventro-medial prefrontal cortex (VMPC), a brain region implicated in the induction of emotions, on a high-risk gambling task known as the Iowa Gambling Task (IGT). This work led Damasio and his colleagues to advance the Somatic Marker Hypothesis (SMH), according to which the autonomic gut feeling response experienced by the normal participants has the potential to guide decision making advantageously and they typically err on the side of caution (although gut feeling can have a negative as well as positive valence). An implication of these findings is that once the neural mechanisms underpinning so-called "gut feelings" are compromised by injury or disease, the consequential absence of the somatic (bodily) signal can be potentially dysfunctional across a variety of decision-making situations.

\section{Exhibit 3}

Hypothesized neural correlates of the C-system supporting reflective social cognition (analogous to controlled processing) and the X-system supporting reflexive social cognition (analogous to automatic processing) displayed on a canonical brain rendering from $(A)$ lateral, $(B)$ ventral, and $(C)$ medial views. Note: the basal ganglia and amygdala are subcortical structures that are displayed here on the cortical surface for ease of presentation. (Source: M.D. Lieberman, 2007, Social Cognitive Neuroscience: A Review of Core Processes. Annual Review of Psychology, Vol. 58, p. 259-289) Copyright $\odot 2007$ by Annual Reviews. All Rights Reserved. Reproduced by kind permission of the publisher

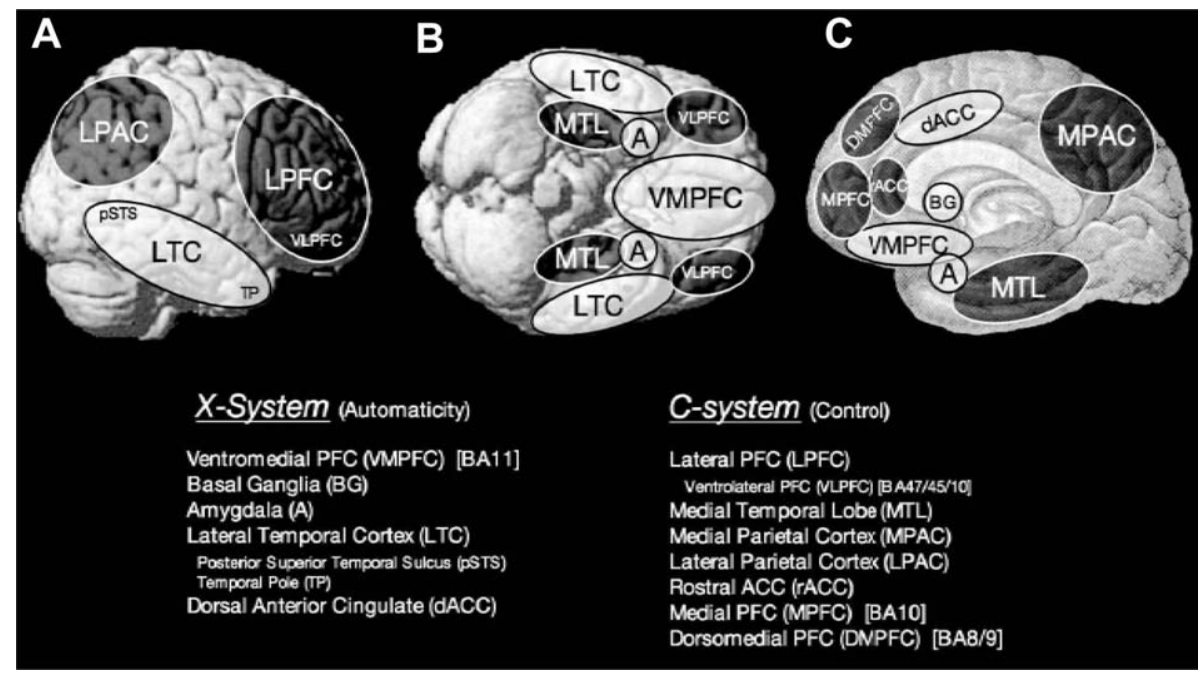




\section{Exhibit 4 \\ The lowa Gambling Task}

In the lowa Gambling Task (IGT) studies, participants chose from four decks of cards; two were rigged to give a modest long-term monetary gain (the "good" decks), while the other two (the "bad" decks) were rigged to give some high gains but even higher losses, culminating in an inevitable long-term loss. Normal participants (i.e. ones without damage to the VMPC) developed a "hunch" for choosing advantageously from the good decks before they were consciously aware which strategy worked best. Moreover, they generated anticipatory skin conductance responses (SCRs) not only before they became consciously aware of the strategy they were adopting, but also before they exercised a risky choice. VMPC-damaged participants, in contrast, gravitated towards the risky, bad decks. Not only did this group continue to choose disadvantageously even after they realised that the correct strategy was to choose from the good decks, they also failed to demonstrate any anticipatory SCRs - figuratively speaking they lacked any "gut feeling" to steer their decisions away from the inevitable monetary loss. ${ }^{21}$

\section{Insights from naturalistic decision making}

The view of "intuition-as-feeling" is complemented by the view of "intuition-as-expertise". In 1987, Herbert Simon described intuitions as analyses frozen into habit and the capacity for rapid response through recognition. Informed, as opposed to naïve, intuitions are "compressed" analyses, executed by decision makers on the basis of perception, recognition and awareness built on learning, experience and feedback and supported by repertoires of action scripts that enable a decision maker to "do what normally works" without decompressing their expertise. Much of the evidence in support of Simon's arguments can now be found in developments in naturalistic decision-making (NDM) research as well as the neuroscience research discussed in the previous section.

NDM researchers examine the ways in which experts take complex, high-stakes, ill-structured decisions under conditions of time pressure, where the opportunity to engage in deliberative, reasoned analysis is severely constrained (for example firefighters faced with the decision of whether or not to evacuate a burning building). The Recognition Primed Decision (RPD) model developed by NDM researcher Gary Klein and his colleagues has shown that domain experts such as firefighters and nurses typically identify a single course of action and follow it through without generating and evaluating multiple alternatives (in a variant of the RPD model, the decision maker may accept or reject a course of action on the basis of a forward projection via mental simulation). As a result of accumulated expertise, domain experts develop complex, domain-relevant mental representations (known as schemas) and associated action scripts, which afford them not only a highly-tuned awareness of the situation, but also the capability to pattern match, in order to sense when something is "out-of-kilter" and intuitively know what actions to perform. In addition to the recognition aspect of intuitive judgment (in the words of Simon "analyses frozen into habit"), the RPD model affords a role for affect in its explanation of the decision making process. In a number of Klein's more revealing case studies, the decision maker's contextual awareness resulted in a particular combination of cues of not "feeling" right, a sense that varied in intensity from unease to anxiety to outright alarm, leading in turn to decisive action taking, with little or no justification beyond these basic affective signals. ${ }^{22}$

In sum, the conjoining of the SMH with the RPD model under the umbrella of dual-process theory provides an integrative and workable account of intuitive decision making for management researchers. Having clarified the nature of intuition and identified the psychological processes underpinning its operation, in the following sections we consider theory and research that has, over a number of decades, investigated how and when managers use intuition. Our aim is to present 


\section{Exhibit 5}

Sample selection of studies of how managers use intuition

\begin{tabular}{|c|c|c|}
\hline Managerial use of intuition & Method & Source $^{25}$ \\
\hline $\begin{array}{l}\text { Sense when a problem exists } \\
\text { Perform well-learned behaviour patterns } \\
\text { rapidly } \\
\text { Synthesize isolated bits of data and experience } \\
\text { into an integrated picture } \\
\text { Check on the results of more rational analysis } \\
\text { Bypass indepth analysis and more rapidly } \\
\text { come up with a plausible solution }\end{array}$ & $\begin{array}{l}\text { Case studies } \\
(N=12)\end{array}$ & Isenberg (1984) \\
\hline $\begin{array}{l}\text { Varies with job level (senior managers are more } \\
\text { intuitive than middle or lower-level managers) } \\
\text { Should be used to help guide strategic decisions, } \\
\text { but is one tool of many to use in guiding decisions } \\
\text { High level of uncertainty and there is little } \\
\text { previous precedent } \\
\text { Variables are unpredictable, and facts are limited } \\
\text { and clearly don't point the way to go } \\
\text { Several plausible alternative solutions exist } \\
\text { and time is limited }\end{array}$ & $\begin{array}{l}\text { Cross-sectional } \\
\text { survey }(N=200)\end{array}$ & Agor (1986) \\
\hline $\begin{array}{l}\text { Most relevant in: corporate strategy and planning; } \\
\text { human resource development; marketing; research } \\
\text { and development; public relations; investment } \\
\text { and diversification; acquisitions, mergers and alliances } \\
\text { Least relevant in: operations and production } \\
\text { management; finance; choosing technology and plant }\end{array}$ & $\begin{array}{l}\text { Cross-sectional survey } \\
(N=1312)\end{array}$ & Parikh (1994) \\
\hline $\begin{array}{l}\text { Personnel or people-related decisions } \\
\text { When decisions need to be made quickly } \\
\text { or unexpectedly } \\
\text { When uncertainty pervades in novel situations } \\
\text { Situations lacking specific cues } \\
\text { In combination with analysis }\end{array}$ & $\begin{array}{l}\text { Interviews with } \\
\text { experienced } \\
\text { professionals }(N=60)\end{array}$ & $\begin{array}{l}\text { Burke and Miller } \\
\text { (1999) }\end{array}$ \\
\hline $\begin{array}{l}\text { Going beyond rational data and information } \\
\text { Using experiences to cut through to the essence } \\
\text { of a situation, make sense of it and test its validity }\end{array}$ & $\begin{array}{l}\text { Cognitive maps of three } \\
\text { strategic decision makers }\end{array}$ & $\begin{array}{l}\text { Clarke and Mackaness, } \\
\text { (2001) }\end{array}$ \\
\hline
\end{tabular}

Note: For Parikh (1994) 'most relevant' are those uses cited by more than 50 per cent of respondents, listed in descending order of importance; vice versa for 'least relevant'.

a balanced account, highlighting both the potential benefits of its skilful deployment and its pitfalls when used indiscriminately, on an uninformed basis.

\section{Managerial use and effectiveness of intuition}

In the 1980s and 1990s, a number of business researchers explored how managers perceive intuition and how they use it across a variety of business contexts. ${ }^{23}$ Exhibit 5 summarizes the findings of 
these studies. A likely precondition for successful intuitive judgment is that the decision maker has domain-relevant expertise and is thus able to exercise informed, as opposed to naïve, intuition and the use of intuition is favoured by managers where the problem is loosely structured, i.e. there is no objective criterion for success (such as in political, ethical, moral or aesthetic judgments) or any pre-conceived solution, and where the decision process needs to be expedited. ${ }^{24}$

The heuristics and biases programme of research instigated by Daniel Kahneman and Amos Tversky countered the rational actor model by demonstrating that in people's everyday judgments, their rapid and automatic "natural assessments", are likely to depart from the laws of logic and probability. In consequence, Kahneman and Tversky and behavioural decision researchers more generally maintained that decision makers are often prone to errors and bias. ${ }^{26}$ The vignettes used in heuristics and biases research are designed in such a way as to reveal the errors that accrue from intuitive judgments in which the laws of probability and statistics are flouted. However, intuition as an adaptive process is ill-suited to such problems, which, unlike the complex problems that confront real-world decision makers, are artificially constrained to meet the requirements of laboratory experimentation. As a result, several more recent developments have led a growing number of researchers to revise the rather downbeat view of intuitive judgment that pervades behavioural decision theory. As well as exploring when and how managers and decision makers deploy intuition, this new breed of organizational decision research has examined the effectiveness of intuitive judgment in business.

In a range of studies, intuitive judgment has been found to be associated positively not only with the quality and speed of decisions, but also the financial and non-financial performance of the wider organization, ${ }^{27}$ while in the context of business venturing, the use of intuition has been found to be higher among entrepreneurs than ordinary managers. Intuitive judgment has also been demonstrated to be related to entrepreneurs' growth intentions and is an important influence during the idea generation stage in new product development. ${ }^{28}$

\section{Intuitive judgment has also been demonstrated to be related to}

\section{entrepreneurs' growth intentions}

Further benefits arising from the skilful deployment of intuition are exemplified by the case studies recounted by Gary Klein and his colleagues in the context of RPD, in situations as diverse as neonatal care and firefighting. ${ }^{29}$ The psychologist Gerd Gigerenzer and his colleagues have demonstrated a number of ways in which decision makers are able to deal successfully with complexity through the adoption of heuristics (i.e. rules of thumb) that are adaptively matched to the structure of the environment. In marked contrast with the rather pessimistic picture of the human mind struggling to overcome computational limitations when faced with risk and uncertainty portrayed by conventional behavioural decision researchers and cognitive scientists, NDM research and the work of Gigerenzer and colleagues present more upbeat accounts of the role of heuristics and intuition as bases for effective decision making. Like intuition, the "fast-and-frugal heuristics" identified by Gigerenzer and his colleagues evolved as part of the adaptive toolbox of the human mind to support effective decision making under time pressure and in the absence of complete information. ${ }^{30}$

Yet a further notion that emphasises the fact that authentic intuition is anything but primitive is Leonard and Swap's notion of "deep smarts", predicated upon an expertise-based view of intuition, in which informed intuitive judgments arise from decision makers' complex, domain-relevant mental representations of the problem. According to Leonard and Swap, deep smarts enable decision makers to quickly comprehend complex, interactive situations by using tacitly-held expertise 
acquired from "first-hand life experiences". Leonard and Swap argue that deep smarts have been observed in many work situations, ranging from the foresighted strategic planning decisions in the Intuit Corporation to the opportunity recognition skills exercised by the multi-millionaire venture capitalist Vinod Kohsla to the difficult-to-articulate best practices embedded in the Toyota Production System. ${ }^{31}$

In summing up each of the developments reviewed in this section, it is clear that each strand of work points to a rather more upbeat account of intuition than has been historically portrayed by behavioural decision researchers, based on a laboratory analysis of what in comparison are lowerlevel heuristics (cognitive shortcuts) that unintentionally flout the laws of probabilistic logic and consequently result in systematic errors of judgment. Contemporary understanding of intuition and the use of heuristics in the workplace is rapidly moving away from such a limited account of human reasoning and judgment. In essence, the type of intuitions in the everyday contexts of business enterprises that form the central focus of this article - that is, affectively-charged judgments based on experts' complex domain relevant schemas - are not equivalent to the subject matter of concern to most conventional behavioural decision researchers. However, although the newer conceptual developments we have outlined show promise, it would be highly disingenuous not to point out that this body of work has yet to be validated with the degree of rigour that has become the hallmark of mainstream behavioural decision research. ${ }^{32}$ Nevertheless, sufficient progress has been achieved that the time has now come to offer a more balanced assessment than the rather extreme positions adopted by many management and behavioural decision researchers.

Responding to a need for a critical evaluation of some of the "hype" that surrounded intuition, especially in the popular management press, Miller and Ireland concluded that intuition can be a troublesome decision tool with benefits that are far from unequivocal. In pursuit of this argument, they defined intuition in two ways. Intuition as "holistic hunch" is based on the creative synthesis of diverse information and experiences; an example is Chrysler's decision, or more correctly, that of its CEO at the time, Jack Welch (of "managing straight from the gut" fame), to develop a very different type of car in the form of the Dodge Viper. Intuition as automated expertise, on the other hand, is essentially a recognition-primed "replay" of steps borne of past learning based on a feeling of familiarity, as in the case of Chevy Chase Bank's routine commercial loan decisions for existing large customers. Miller and Ireland came to the view that holistic hunch intuition is beneficial but only when companies are in an exploration phase (for example when seeking new technologies and strategies), while automated expertise intuition yields disappointing outcomes in exploratory behaviour but may also yield unpredictable outcomes in situations calling for the straightforward use of past learning. Miller and Ireland suggested that the troublesome nature of automated (tacit) intuitive judgment may be addressed by raising the decision process to an explicit level through techniques such as devil's advocacy or balancing intuitive judgment with formal analytical tools (such as multi-attribute decision analysis and root cause analysis). ${ }^{33}$

\section{Implications for the assessment, development and management of intuition in the workplace}

In this final section, we consider a number of strategies to optimise information processing capabilities at the individual and group levels, with a view to leveraging the benefits of intuition in the enhancement of strategic competence. In line with dual-process conceptions of judgment and decision making, skilled strategic decision making requires the blending of intuitive and analytic approaches to information processing in ways that enable the decision-making unit, whether an individual, group or multiple groups, to appreciate important details, while also maintaining a bigger picture. ${ }^{34}$ How then might organizations best equip their strategists with the ability to switch between analytical and intuitive processing so as to make more intelligent use of their intuitions? To what extent is it possible to develop this switching capability in individuals? Or is this a trait-based capability, thus implying a role for personnel selection so as to optimize the configuration of decision-making groups? 


\section{Acquiring intuitive expertise}

Studies of expert performance suggest that it can be enhanced considerably through intense practice, critical self-appraisal and candid feedback. For example, research into the role of expertise in chess has indicated that chess Masters are capable of recognising and acting on as many as 50,000 meaningful patterns, acquired over at least 10 years and approximately 10,000 hours of study and practice. ${ }^{35}$ As noted earlier, intuitive expertise enables decision makers to frame problems rapidly and identify the appropriate course of action long before they are able to articulate their reasoning as to why that course of action is appropriate. However, this rapidity of execution is far from the "innate genius" type of action often attributed to prodigies such as Mozart; rather, it is the product of intensive learning, practice and feedback. Mintzberg's recently published critique of mainstream management development and management education programmes bears out this analysis. ${ }^{36}$ According to Mintzberg, conventional management development programmes, as taught in mainstream business schools, have overly privileged conceptual knowledge at the expense of expertise borne out of experience. Skilled management practice is, he says, as much "art" based on insight, vision and intuition, as it is science.

The development of expertise and the concomitant capacity for intuition is an arduous journey; it is not attained merely through the successful completion of a formal management qualification and/ or limited on the job experience; on the contrary, it requires a blending of conceptual/analytical knowledge, probably best gained in the classroom, with experiential knowledge, gained through years of exposure to challenging problems in the workplace. In other words, formal management education needs to be allied to a programme of ongoing professional development. Deliberate practice, accompanied by candid but constructive, feedback is the order of the day. K. Anders Ericsson, the expertise researcher, and his colleagues have shown that the deliberate practice that builds genuine expertise requires both depth and breadth of engagement; hence, managers should not focus solely on improving the skills they already possess, which merely enables the development of the habitual responses needed to deal with common or familiar problems. Rather, they also need to move outside their comfort zones to extend their strategic competence profiles, thereby equipping themselves with the skills to deal with less common problems. ${ }^{37}$ Feedback is critically important in this process, but it is not merely the fact that feedback is invited, given or received that is important; instead, the type and quality of feedback and the learning that results from it are also vitally important. Robin Hogarth, decision researcher, distinguishes between two types of learning environment: those that have "kind learning structures" enhance intuition by affording effective feedback; "wicked structures for learning", in contrast, are contexts that suppress intuition. In other words, they lead to the development of poor intuitive judgment by affording only limited, low-quality feedback, as for example when a CEO's intuitions go routinely unchallenged. ${ }^{38}$ Ultimately, it is the combination of focused and deliberate conceptual and experiential development in a feedback-rich environment that makes for an appropriately rounded manager, i.e. one capable of authentic reflexivity.

\section{Formal management education needs to be allied to a vigorous}

\section{programme of ongoing professional development}

\section{Developing self-awareness}

Individual differences theorists distinguish between cognitive styles and cognitive strategies. The former refers to enduring overarching preferences in approach to the processing of information, whereas the latter are approaches adopted in response to particular circumstantial demands. ${ }^{39}$ Providing managers with feedback on their preferred approach (i.e. their cognitive style) to information processing is an important prerequisite for enabling them to explore, develop and ultimately deploy 
alternative approaches (i.e. cognitive strategies) in situations where their preferred ways of thinking are inappropriate and/or difficult to execute. In order to acquire such meta-cognitive skills, strategic decision makers must first be made aware of their cognitive style through psychometric profiling, and in so doing, they may become more reflective in their own practices. Fortunately, there are a growing number of robust psychometric instruments that are easy to administer in workplace settings for the purposes of personnel selection, assessment and development, the design of which are in keeping with current dual-process theories of judgment and decision-making. ${ }^{40,41}$

A $2 \times 2$ typology based on a contemporary dual-process conceptualization of cognitive styles and strategies was suggested by Hodgkinson and Clarke. ${ }^{42}$ As shown in Exhibit 6, "detail conscious individuals" are highly analytic with little regard for intuition. As a consequence, they are prone to becoming overburdened by the demands of the situation, unable to extract the bigger picture, particularly when operating under time pressure. "Big picture conscious" individuals, in contrast, are highly intuitive, preoccupied with gaining an overview of the situation or problem at the expense of detail. Hence, they run the risk of overlooking vital information. "Non-discerning" individuals deploy minimal cognitive resources, being disinclined to process details or extract a bigger picture, relying on the received wisdom of others, while "cognitively versatile" individuals are predisposed equally to processing detail and cutting through such detail to intuit a broader perspective. Cognitive versatility is the most valued approach for strategic decision making, enabling individuals to blend and flex to the varying information processing demands, as and when required to do so. Clearly, the typology offered in Exhibit 6, especially when used in conjunction with appropriate psychometric tools of assessment, provides a useful starting point for fostering self-awareness among those involved in strategizing activity.

Sadler-Smith and Shefy have offered guidelines for the development of intuitive awareness (summarized in Exhibit 7), which have been implemented successfully on MBA programmes. ${ }^{43}$ More generally, the extent to which training and development activities designed to encourage managers to acquire the requisite blend of analytic and intuitive approaches yield tangible improvements in the strategy-making process, and on what basis they do so, is not yet fully understood. To the extent that individual differences in the processing of information are relatively stable, trait-like

\section{Exhibit 6}

Basic typology of contrasting cognitive strategies and styles (Source: G.P. Hodgkinson and I. Clarke, 2007, 'Exploring the cognitive significance of organizational strategizing: A dual-process framework and research agenda,' Human Relations, 60, 243-255). (C2007 by Sage Publications. Reproduced by kind permission of the publisher

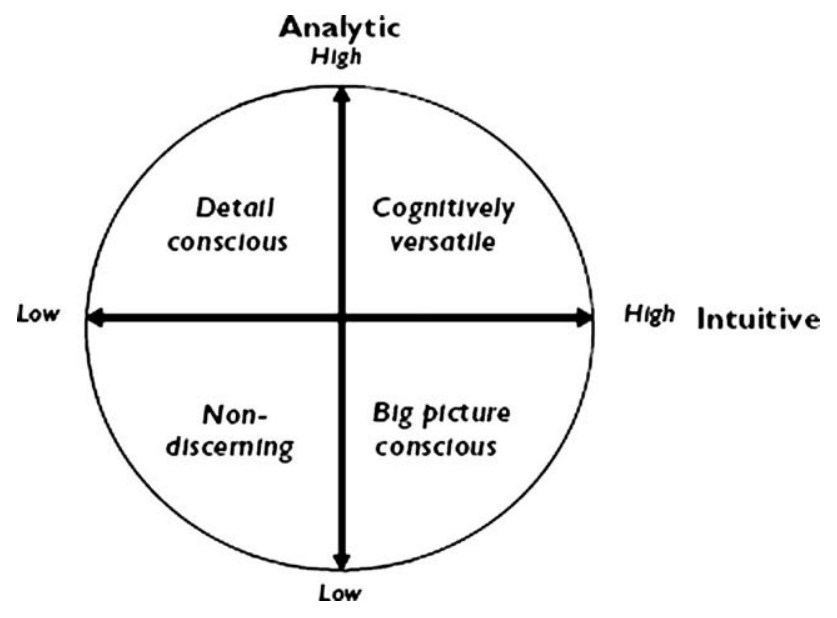




\section{Exhibit 7}

Guidelines for developing intuitive awareness (Source: E. Sadler-Smith and E. Shefy, 2004, The intuitive executive: understanding and applying 'gut feel' in decision making, Academy of Management Executive, 18(4), 76-91). (C2004 by The Academy of Management. Reproduced by kind permission of the publisher
1. Open up the closet
To what extent do you: experience intuition; trust your feelings; count on intuitive judgments; suppress hunches; covertly rely upon gut feel?
2. Don't mix up your I's
Instinct, insight, and intuition are not synonymous; practice distinguishing between your instincts, your insights, and your intuitions.
3. Elicit good feedback Seek feedback on your intuitive judgments; build confidence in your gut feel; create a learning environment in which you can develop better intuitive awareness.
4. Get a feel for your batting average Benchmark your intuitions; get a sense for how reliable your hunches are; ask yourself how your intuitive judgment might be improved.
5. Use imagery
6. Play devil's advocate
Use imagery rather than words; literally visualise potential future scenarios that take your gut feelings into account. Test out intuitive judgments; raise objections to them; generate counterarguments; probe how robust gut feel is when challenged.
7. Capture and validate your intuitions Create the inner state to give your intuitive mind the freedom to roam; capture your creative intuitions; $\log$ them before they are censored by rational analysis.

phenomena, there are likely to be upper limits to the attainment of strategic competence through this route. Moreover, in conditions of severe pressure, it is possible that individuals, albeit welltrained, may revert to their natural information-processing tendencies. However, we should not lose sight of the fact that in particular circumstances, the extreme analytic or extreme intuitive may have competencies that are uniquely suited to solving particular classes of problems or taking certain types of decisions. ${ }^{44}$

\section{Managing the strategic decision making unit's composition}

An alternative means of enhancing the information processing capabilities of the organization that might overcome some of the potential limitations of the training and development approach outlined above is to adopt selection practices designed to ensure that strategy-making teams are composed in such a way that the requisite blend of analytic and intuitive capabilities are distributed across the team. Extrapolating from the arguments outlined at the individual level to the team level, in the case of strategy-making groups dominated by an overly analytical approach, there is a potential danger of acute information overload and loss of the bigger picture, compounded by the fact that multiple individuals with a keen eye for detail are pooling information. Conversely, to the extent the individuals comprising the decision-making unit are marked by an overarching preference for an intuitive approach to processing information, the principal danger is that decisions will be made in the absence of a sufficiently comprehensive understanding of the situation. Suitably balanced teams, in contrast, have the potential to function more optimally in terms of processing information, by virtue of possessing the requisite variety of cognitive styles and strategies. Members of strategy-making units may be selected in such a way that the unit possesses the requisite mix of 
stylistic preferences (analytic and intuitive). Unfortunately, however, as will be discussed in the next section, balancing the team is not without potential difficulties.

\section{Developing effective leaders for cognitively-diverse strategic decision making units}

Attaining the optimal blend of intuitive and analytically-inclined individuals within the strategymaking unit places a premium on the capabilities of the group's leader. A key task of the strategic leader is to effectively manage strategy-making units composed of cognitively-diverse individuals. A crucial leadership skill is to be able to manage effectively and empathically the dynamics arising from the diversity of processing strategies and styles at work. In order to minimize the potentially deleterious impact of such diversity, it is imperative that individuals gain an indepth appreciation of the relative strengths and limitations of one another's approaches, so as to foster mutual respect and trust within the strategy-making unit. ${ }^{45}$

It is also essential that individuals are given the time and space to raise their natural concerns in such a way that emotions can be authentically expressed, to the extent required for participants to bring their underlying differences to a satisfactory resolution, recognising that the strategizing process is more than an exercise in thinking; it is both an inherently cognitive and affective process. Hence a key task of the leader is to allow gut feelings and hunches to surface, in order to enable debate and the development of shared meaning. In this way, consequent solutions to strategic problems can be advanced beyond a superficial level, participants owning both the process and associated outcomes. In the absence of such authentication processes, task and interpersonal conflict are likely to escalate, undermining the effectiveness of the decision making unit, for as demonstrated by the work of Michael Kirton and his colleagues, teams composed of individuals with a diverse mix of cognitive styles do not always make easy bedfellows. ${ }^{46}$

\section{Intuition and the development of shared meaning}

Much work has been devoted to operationalizing how managers' representations of knowledge can be mapped and modelled. Intuitions are subjective, experientially rooted judgments (albeit derived from explicit and implicit learning processes) that arise through rapid, non-conscious holistic associations founded on largely tacit ways of knowing. One implication of this assertion is that intuitions may challenge or even defy expression by symbolic means, i.e. language. While language plays a pivotal role in articulating analytical cognition, it inevitably falls short in attempts to articulate intuitive and other forms of non-conscious cognition. Nonetheless, decision makers in the social setting of business organizations must be able to account in some way for their "gut feel" interpretation of events and their intuitive judgments. As observed by Klein, they may do this in several ways, including the use of storytelling to connect observed events or by employing metaphors to provide an analogue or image. The use of stories and metaphors provides a potentially powerful means by which intuitions can be articulated to develop a shared understanding of the situation.

However, Klein has also pointed out that a potential downside of this approach to surfacing intuitive knowledge for collective consumption is the production of a problematic "mindset" - in other words, constructing a story to account for an intuition and then using available data to confirm it. The story or the metaphor is a translation into symbolic means of an affective state. Consequently, it is not equivalent to the affective state itself, the latter by definition being purely subjective. Exhortations to individuals to be open-minded to these potential sources of inaccuracy and bias may be unrealistic. Hence, Klein's advice is to construct such stories while being prepared to find flaws in their interpretations, to appreciate one's fallibility and that of the wider group, and to acknowledge that intuitions can be wrong, accompanying feelings of certitude notwithstanding. ${ }^{47}$

\section{Intuition and creative cognition}

One area in which the cognitive diversity of strategic decision-making teams is especially significant in the contemporary business world is in relation to creativity and innovation. In situations that demand idea generation and divergent thinking, consciously-controlled, logically-justified, 


\section{Exhibit 8}

\section{Lessons for managers}

- Acquiring intuitive expertise

- A careful blending of experiential and conceptual/analytical knowledge gained through years of exposure to challenging problems in the workplace supported by classroom experience and "kind learning structures".

- Developing self awareness

- Making people aware of their cognitive style, which can range from "detail conscious (wholly analytical)" to "big picture consciousness" (wholly intuitive).

- Managing strategic decision making

- Considering making the team a mixture of (competent) people with cognitively diverse styles of reasoning

- Developing leaders for mixed teams, recognising that teams composed of a diverse mix do not always make easy bedfellows and can be counterproductive.

- Encouraging those with strong intuition to develop stories to explain their intuition, yet recognizing that these stories are not "proofs".

- Creative situations

Recognizing that situations that demand creativity also demand intuition, but that this is not always the same as intuition gained from experience.

error-free and "right first time" analytical cognition may not be the best tool. Cognitive strategies that work well for problems that are well-defined and open to objective decomposition will be much less effective when the problem is ill-defined and cannot be analysed into objective components. The creative cognition required by this latter class of problems is the antithesis of the accepted view of being "clever" and "decisive": it is "fuzzy", vague, unjustified, experimental, empathic and slow - a state captured succinctly by the poet Keats through his notion of negative capability: "when man is capable of being in Mysteries, Doubts and Uncertainties, without any irritable reaching after fact and reason". Making time available to perceive and think more slowly makes possible broader cognitions, more abstract thinking and greater flexibility. These cognitions manifest themselves as "inklings" or "glimmerings" - i.e. intuitions of an understanding not yet achieved.

The creative cognitions that manifest themselves as intuitions (intimations or feelings of knowing) operate at the other end of the speed continuum than that occupied by the lightening-fast expertise-based judgments that arise in response to the complex, time-pressured situations of the type studied by NDM and expertise researchers. Allowing for a period of incubation creates space for mental relaxation and the consequent removal of analytical blocks, for serendipitous associations to occur and enables the slow spreading of activation trails that may throw up a new metaphor, perspective or connection that conjoins previously unrelated elements. The intuitive facet of creativity is not only a complex and ambiguous competency to recognise and assess, it is also difficult to accommodate within organizational cultures and structures that scorn fallibility and prohibit experimentation, risk taking and departures from efficient standard operating procedures. The creative cognitions that are one outcome of non-conscious intuitive processes are, like their analytical counterparts, fallible, but nonetheless essential to the generation and exploration of novel ideas in preparing viable alternatives for business success. ${ }^{48}$

\section{Summary and Conclusions}

Over recent decades, intuition research has moved increasingly to the fore in the behavioural sciences. Much progress has been made in transforming the notion of intuition from a construct that was previously consigned to the fringes of the major disciplines in this area to one in which the 
insights of many of the major branches of psychology and neuroscience have been synthesized into a compelling theoretical framework. Hence, the rapidly-expanding developments in social cognitive neuroscience reviewed in this article look set to further substantiate and extend current understanding of intuition, providing vital scientific foundations for its increasing role in organizational life as well as a framework of lessons for managers (summarized in Exhibit 8). ${ }^{49}$

More work still needs to be done to establish a firm base upon which to build application-orientated implications for organizations and managers. Further work might include the development of a more explicit representation of the constructs closely aligned with, yet distinct from, intuition (e.g. instinct, insight, judgment, creativity, tacit knowledge, implicit learning, wisdom and deep smarts). ${ }^{5}$ Such clarification should enable deeper and more probing investigations, not only into the conditions under which executives use intuition, but also a clearer picture of the specific circumstances in which it is likely to be effective. An inevitable consequence of positive developments in this regard will be the incorporation of intuition into mainstream management education. Researchers and practitioners can now look forward to a time when the notion of intuition is not only a valid, reliable and well-theorised construct, with firm empirical foundations, but is also recognised and accepted as an indispensable element of the competence base of the successful business executive.

\section{Acknowledgements}

This article arose from a symposium hosted under the auspices the UK Economic and Social Research Council (ESRC)/Engineering and Physical Sciences Research Council (EPSRC) Advanced Institute of Management (AIM) Research, London, in September 2006. The authors are grateful to the workshop participants for their helpful and constructive comments and suggestions on their oral presentations, which formed the basis of the work reported. The financial support of AIM Research in the preparation of this article (under grant number RES-331-25-0028, awarded to the first-named author) is also gratefully acknowledged.

\section{References}

1. J. Clemens and D. Mayer, The Classic Touch: Lessons in Leadership from Homer to Hemingway, Contemporary Books, Chicago, (1999) pp. 166-167. A. Morita, Selling to the world: the Sony Walkman story, in J. Henry and D. Walker (eds.), Managing Innovation, Sage Publications, London, 191 (1991); Genentech Annual Report (2000).

2. Various of the strands of psychological theory and research underpinning this article are surveyed more extensively in, G. Claxton, Knowing without knowing why, The Psychologist, 217-220 (May 1998); and G. P. Hodgkinson, J. Langan-Fox and E. Sadler-Smith, Intuition: a fundamental bridging construct in the behavioural sciences, British Journal of Psychology 99, 1-27 (2008).

3. R. A. D’Avini, Hypercompetition, Free Press, New York (1994); A. Y. Ilinitch, A. Y. Lewin and R. A. D'Aveni, Introduction, in A. Y. Ilinitch, A. Y. Lewin and R. A. I. D'Aveni (eds.), Managing In Times of Disorder: Hypercompetitive Organizational Responses, Sage, Thousand Oaks, CA (1998). The notion of increasing hypercompetition is by no means universally accepted. See, for example, G. McNamara, P. M. Vaaler and C. Devers, Same as it ever was: the search for evidence of increasing hypercompetition, Strategic Management Journal 24, 261-278 (2003).

4. C. I. Barnard, The Functions of the Executive, Harvard University Press, Cambridge, MA (1938); H. A. Simon, Administrative Behavior, MacMillan, New York (1947); H. A. Simon, Making management decisions: the role of intuition and emotion, Academy of Management Executive 12, 57-64 (1987). For more extensive overviews of the literature pertaining to the cognitive capabilities and limitations of organizations and the individuals and groups within them, see G. P. Hodgkinson and P. R. Sparrow, The Competent Organization: A Psychological Analysis of the Strategic Management Process, Open University Press, Buckingham, UK (2002); G. P. Hodgkinson and M. P. Healey, Cognition in organizations, Annual Review of Psychology 59, 387-417 (2008).

5. Hodgkinson and Sparrow (2002).

6. G. Lakoff and M. Johnson, Philosophy in the Flesh: The Embodied Mind and its Challenge to Western Thought, Basic Books, New York (1999). 
7. Claxton (1998) 217-220.

8. See, for example, A. M. Hayashi, When to trust your gut, Harvard Business Review 59-65 (February 2001); W. Duggan, Strategic Intuition: The Creative Spark in Human Achievement, Columbia Business School Publishing, New York (2007). The observation of Ralph S. Larsen, former CEO of Johnson \& Johnson and now a director at GE, illustrates the tendency managers to conflate intuition with instinct. He once claimed: "Every time I have been burned in decision making it is because I have gone against my instincts." quoted in J. Clemens and D. Mayer, The Classic Touch: Lessons in Leadership from Homer to Hemingway, Contemporary Books, Chicago, (1999) p. 166. Interestingly, even the current UK science minister, Lord Drayson, seems to conflate the notion of intuition with instinct. See I saw it coming, says minister of sixth sense Lord Drayson, The Sunday Times (16 Nov 2008).

9. For a more detailed discussion of such accounts see E. Sadler-Smith, Inside Intuition, Routledge, Abingdon (2008).

10. Ilg and colleagues described the processes underlying intuitive coherence judgments as involving the spread of neural activation between associated concepts in memory, which may not be strong enough to support conscious retrieval. In other words, spreading activation operates beneath the level of conscious awareness and in this sense is a "covert" process, but nonetheless gives rise to an intuitive impression of coherence. It thus has the potential to bias conscious judgment. Phenomenally, the intuitive impression is similar to the "tip of the tongue" experience. Ilg and colleagues are also careful to distinguish between intuition (a general problem-solving mode, which is based on the implicit processing of unconsciously-activated material) and insight (the sudden realisation of a solution originating from a covert process). See R. Ilg, K. Vogeley, T. Goschke, A. Bolte, J. N. Shah, E. Pöppel and G. R. Fink, Neural processes underlying intuitive coherence judgments as revealed by fMRI on a semantic judgment task, NeuroImage 38, 228-238 (2007). See also R. J. Sternberg and J. E. Davidson (eds.), The Nature of Insight, The MIT Press, Cambridge, MA (1995).

11. See M. Bowden, M. Jung-Beeman, J. Fleck and J. Kounios, New approaches to de-mystifying insight, Trends in Cognitive Sciences 9, 322-328 (2005); K. G. Volz and D. Y. von Cramon, What neuroscience can tell about intuitive processes in the context of perceptual discovery, Journal of Cognitive Neuroscience 18, 2077-2087 (2006).

12. E. Sadler-Smith and E. Shefy, The intuitive executive: understanding and applying "gut feel" in decision making, Academy of Management Executive 18, 76-91 (2004); C. C. Miller and R. D. Ireland, Intuition in strategic decision making: friend or foe in the fast-paced 21st century?, Academy of Management Executive 19, 19-30 (2005); E. Dane and M. G. Pratt, Exploring intuition and its role in managerial decision making, Academy of Management Review 32, 33-54 (2007).

13. Dane and Pratt have recently proposed a new taxonomy of intuition, which distinguishes creative, problem solving and moral forms of intuition in the workplace. According to Dane and Pratt, creative intuition, like insight, is accompanied by an incubation period. For further details see: E. Dane and M. G. Pratt, Conceptualizing and measuring intuition: a review of recent trends, in G. P. Hodgkinson and J. K. Ford (eds.), International Review of Industrial and Organizational Psychology Vol. 24, Wiley, Chichester, UK, 1-40 (2009).

14. S. Chaiken and Y. Trope (eds.), Dual-Process Theories in Social Psychology, Guilford Press, New York (1999); J. St. B. T. Evans, In two minds: dual-process accounts of reasoning, Trends in Cognitive Sciences 7, 454-459 (2003); K. E. Stanovich and R. F. West, Individual differences in reasoning: implications for the rationality debate?, Behavioral and Brain Sciences 23, 645-665 (2000).

15. S. Epstein, Integration of the cognitive and the psychodynamic unconscious, American Psychologist 49, 709-724 (1994); S. Epstein, Intuition from the perspective of cognitive-experiential self-theory, in H. Plessner, C. Betsch and T. Betsch (eds.), Intuition in Judgment and Decision Making, Lawrence Erlbaum Associates, New York, 23-37 (2008).

16. Evans 454-459 (2003); J. St. B. T. Evans, Dual-processing accounts of reasoning, judgment, and social cognition, Annual Review of Psychology 59, 255-278 (2008); Stanovich and West (2000), 645-665. K. E. Stanovich, Who is Rational? Studies of Individual Differences in Reasoning, Mahwah, NJ (1999). Epstein (1994) 709-724. Epstein (2008) 23-37; S. Epstein, R. Pacini, V. Denes-Raj and H. Heier, Individual differences in intuitive-experiential and analytical-rational thinking styles, Journal of Personality and Social Psychology 71, 390-405 (1996).

17. As observed by Satpute and Lieberman (2006), dual-process conceptions and the recent advances in social cognitive neuroscience have evolved largely independently of one another. However, there is sufficient common ground to conclude that there are close parallels between the essential elements of dual-process models and the neural systems identified by Lieberman and his colleagues. For details see A. B. Satpute 
and M. D. Lieberman, Integrating automatic and controlled processes into neurocognitive models of social cognition, Brain Research 1079, 86-97 (2006).

18. H. Mintzberg, Planning on the left side and managing on the right, Harvard Business Review 54, 49-58 (1976). See also J. Hayes and C. W. Allinson, Cognitive style and its relevance for managerial practice, British Journal of Management 5, 53-71 (1994).

19. See, for example, J. Hayes and C. W. Allinson, Cognitive style and the theory and practice of individual and collective learning in organizations, Human Relations 51(7), 847-871 (1998).

20. These developments notwithstanding, a number of leading scholars in strategic management still continue to deploy the basic left brain-right brain nomenclature. See, for example, D. J. Teece, Explicating dynamic capabilities: the nature and microfoundations of (sustainable) enterprise performance, Strategic Management Journal 28, 1319-1350 (2007).

21. A. Bechara, H. Damasio, D. Tranel and A. R. Damasio, Deciding advantageously before knowing the advantageous strategy, Science 275, 1293-1294 (1997); A. R. Damasio, Descartes' Error: Emotion, Reason and the Human Brain, HarperCollins, New York (1994).

22. G. Klein, Sources of Power: How People Make Decisions, The MIT Press, Cambridge, MA (1998); G. Klein, Intuition at Work, Currency Doubleday, New York (2003).

23. W. A. Agor, The logic of intuition: how top executives make important decisions, Organizational Dynamics 13(4), 5-18 (1986); L. A. Burke and M. K. Miller, Taking the mystery out of intuitive decision-making, Academy of Management Executive 13, 91-99 (1999); I. Clarke and W. Mackaness, Management "intuition": an interpretative account of structure and content of decision schemas using cognitive maps, Journal of Management Studies 38(2), 147-172 (2001); Hayashi (2001) 59-65; D. J. Isenberg, How senior managers think, Harvard Business Review 81-90 (November/December 1984); J. Parikh, Intuition: The New Frontier of Management, Blackwell Business, Oxford (1994).

24. Klein (2003); P. Laughlin, Social combination processes of cooperative problem-solving groups on verbal intellective tasks, in M. Fishbein (ed.), Progress in Social Psychology Vol. 1, Lawrence Erlbaum Associates Hillsdale, NJ, 127-155 (1980); E. Sadler-Smith and P. R. Sparrow, Intuition in organizational decision- making, in G. P. Hodgkinson and W. H. Starbuck (eds.), The Oxford Handbook of Organizational Decision Making, Oxford University Press, Oxford, 305-324 (2008); S. Shapiro and M. T. Spence, Managerial intuition: a conceptual and operational framework, Business Horizons 40(1), 63-68 (1997).

25. Isenberg (1984) 81-90. Agor (1986) 5-18. Parikh (1994). Burke and Miller (1999) 91-99. Clarke and Mackaness, (2001) 147-172.

26. See, for example T. Gilovich and D. Griffin, Introduction - heuristics and biases: then and now, in T. Gilovich, D. Griffin and D. Kahneman (eds.), Heuristics and Biases: The Psychology of Intuitive Judgment, Cambridge University Press, Cambridge, 1-8 (2002).

27. C. W. Allinson and J. Hayes, The cognitive style index: a measure of intuition-analysis for organizational research, Journal of Management Studies 33, 119-135 (1996); J. R. Hough and dt. Ogilvie, An empirical test of cognitive style and strategic decision outcomes, Journal of Management Studies 42(2), 417-448 (2005); N. Khatri and H. A. Ng, The role of intuition in strategic decision-making, Human Relations 53, 57-86 (2000); W. J. Ritchie, R. W. Kolodinsky and K. Eastwood, Does executive intuition matter? An empirical analysis of its relationship with non-profit organization financial performance, Non-profit and Voluntary Sector Quarterly 36, 140-155 (2007); E. Sadler-Smith, Cognitive style and the performance of small and medium sized enterprises, Organization Studies 25, 155-182 (2004).

28. D. K. Dutta and S. Thornhill, The evolution of growth intentions: towards a cognition-based model, Journal of Business Venturing 23, 307-332 (2008); D. Ravasi and C. Turati, Exploring entrepreneurial learning: a comparative study of technology projects, Journal of Business Venturing 20, 137-164 (2005). C. W. Allinson, E. Chell and J. Hayes, Intuition and entrepreneurial performance, European Journal of Work and Organizational Psychology 9(1), 31-43 (2000).

29. Klein $(1998,2003)$.

30. A useful illustration of a fast and frugal heuristic is the "recognition heuristic" identified by Gigerenzer and his team. This particular heuristic, deployed in situations where a decision maker must make inferences in respect of two alternatives, capitalises on the decision maker having a "beneficial degree of ignorance" in connection with one of those alternatives, such that they will infer that the alternative about which they are more knowledgeable has greater value. For example, when German students were asked whether Detroit or Milwaukee had the higher population, most of them got it right on the basis that they had heard of Detroit but not Milwaukee. US students, in contrast, fared considerably less well than their German counterparts because they were familiar with both alternatives; hence, they tended 
to deliberate. More generally, Gigerenzer and his colleagues have investigated the utility of a variety of fast and frugal heuristics in a diverse range of business-related contexts, from consumer choice to decisions pertaining to investment portfolios. For a more extensive discussion of the links between fast and frugal heuristics, intuition and the adaptive tool box notion, see G. Gigerenzer, Gut Feelings: The Intelligence of the Unconscious, Allen Lane, London (2007).

31. D. Leonard and W. Swap, Deep Smarts: How to Cultivate and Transfer Enduring Business Wisdom, Harvard Business School Press, Boston, MA (2005). Some advocates of scenario planning and related forecasting techniques directed at challenging decision makers' underlying assumptions maintain that expertise-based intuition, informed by processes akin to the notions of RPD and deep smarts, is a vital ingredient in the construction of plausible alternative frames for managing in times of risk and uncertainty. Viewed from this perspective, the fast, unconscious pattern recognition associated with RPD and deep smarts has a generative function in that it enables experienced decision makers to aggregate information that appears fragmented to the novice into meaningful patterns which facilitates not only recognition but also forward projection into uncertain futures. See, for example, K. van der Heijden, R. Bradfield, G. Burt, G. Cairns and G. Wright, The Sixth Sense: Accelerating Organizational Learning With Scenarios, John Wiley, Chichester (2002); P. Saffo, Six rules for effective forecasting, Harvard Business Review 122-131 (July-August 2007).

32. For further critical assessments of progress in respect of NDM and work on fast and frugal heuristics see: G. Gigerenzer, How to make cognitive illusions disappear: beyond heuristics and biases, in W. Stroebe and M Hewstone (eds.), The European Review of Social Psychology Vol. 2, Wiley, Chichester, 83-115 (1991); G. Gigerenzer and D. G. Goldstein, Reasoning the fast and frugal way: models of bounded rationality, Psychological Review 103, 650-669 (1996); D. Kahneman and A. Tversky, On the reality of cognitive illusions, Psychological Review 103, 582-591 (1996); R. Lipshitz, G. Klein, J. Orasanu and E. Salas, Focus article: taking stock of naturalistic decision making, Journal of Behavioral Decision Making 14, 331-352, (2001) [accompanied by 16 peer commentaries]. Hodgkinson and Healey (2008) 387-417. Hodgkinson, Langan-Fox and Sadler-Smith (2008) 1-27. Hodgkinson and Sparrow (2008).

33. See Miller and Ireland (2005) 19-30. Not surprisingly, this tension concerning the relative merits and limitations of intuition as a basis of managerial decision making has been similarly played out in the realms of pedagogy. The Operational Research Society, UK, for example, markets its executive development courses on decision making on the basis that successful organizational decision makers are ones who take "bolder decisions with less gut-feel", downplaying the significance of intuition while accentuating the virtues of "advanced analytical methods to help make better decisions" (for further details visit: The Operational Research Society website at: http://www.theorsociety.com/science_of_better/htdocs/prospect/or_executive_guide.pdf/ — accessed 19th November 2008 at 13:29 and 25 seconds). Conversely, we know of at least one leading business school whose internationally-recognised MBA programme is designed: "to look beyond business processes and techniques to emphasise self-awareness, intuition, cross-cultural sensitivity and entrepreneurship skills as well as a socially responsible and ethical approach to business and management": http://www.bath.ac.uk/management/courses/mba/ — accessed 15th November 2008 at $11: 43$ and 47 seconds).

34. M. R. Louis and R. I. Sutton, Switching cognitive gears: from habits of mind to active thinking, Human Relations 44, 55-76 (1991); G. P. Hodgkinson and I. Clarke, Exploring the cognitive significance of organizational strategizing: a dual-process framework and research agenda, Human Relations 60, 243-255 (2007).

35. W. G. Chase and H. A. Simon, Perception in chess, Cognitive Psychology 4, 55-81 (1973).

36. H. Mintzberg, Managers Not MBAs, Berrett-Koehler Publishers, San Francisco (2004); See also K. A. Ericsson, M. J. Prietula and E. T. Cokely, The making of an expert, Harvard Business Review 115-121 (July-August 2007).

37. Ericsson et al. (2007) 115-121.

38. R. M. Hogarth, Educating Intuition, The University of Chicago Press, Chicago (2001).

39. See Hayes and Allinson (1994) 53-71.

40. Candidate instruments for these purposes include the Rational Experiential Inventory (REI) developed by Epstein and colleagues, the Preference for Intuition and Deliberation (PID) scales developed by Betsch, and the scales devised by Anthony and Daake for the assessment of analytic and intuitive processing. The Cognitive Style Index (CSI), developed by Allinson and Hayes, is also potentially of value in this context, with the proviso that the scoring procedure is adapted in line with dual-process theories of cognition. For further details of these instruments see: W. P. Anthony and D. Daake, Measurement of Analysis and Tacit Knowledge in Decision Making (Unpublished working paper), Florida State University (1994); R. H. Bennett and W. P. Anthony, Understanding the role of intuition-tacit knowledge and analysis-explicit knowledge in bank board deliberations, in T. K. Lant and Z. Shapira (eds.), Organizational 
Cognition: Computation and interpretation, Lawrence Erlbaum Associates, New York (2001); Epstein et al. (1996) 390-405; S. Epstein, R. Pacini and P. Norris, The Rational-Experiential Inventory, Unpublished inventory, University of Massachusetts at Amherst (1998); G. P. Hodgkinson and E. Sadler-Smith, Complex or unitary? A critique and empirical re-assessment of the Allinson-Hayes Cognitive Style Index, Journal of Occupational and Organizational Psychology 76, 243-268 (2003); C. Betsch, Praferenz fur intuition und deliberation, Inventar zur Erfassung von affect- und kognitionsbasiertem entscheiden [Preference for intuition and deliberation (PID): an inventory for assessing affect- and cognition-based decision-making], Zeitschrift fur Differentielle und Diagnostische Psychologie 25, 179-197 (2004); C. Betsch, Chronic preferences for intuition and deliberation in decision making: lessons learned about intuition from an individual differences approach, in H. Plessner, C. Betsch and T. Betsch (eds.), Intuition in Judgment and Decision Making, Lawrence Earlbaum Associates, New York, 231-248 (2008).

41. Given that these instruments rely on self-report procedures, when used in isolation they are ultimately of questionable value as a basis for determining the contribution of information processing styles and strategies to task performance. For this reason, Hodgkinson et al. (2008) have advocated the use of laboratory tasks designed to induce variously analytic and intuitive strategies. When used in conjunction with other methods, such as the aforementioned self-report measures of cognitive strategies and styles, and/or cognitive task analysis procedures and related cognitive mapping techniques, laboratory tasks provide a potentially powerful means for determining the validity of self-based knowledge. In a particularly exciting development, Lieberman and his colleagues have used functional magnetic resonance imaging (fMRI) in conjunction with reasoning tasks. See M. D. Lieberman, J. M. Jarcho and A. B. Satpute, Evidence-based and intuition-based self-knowledge: an fMRI study, Journal of Personality and Social Psychology 87, 421-435 (2004); Hodgkinson et al. (2008) 1-27.

42. Hodgkinson and Clarke (2007) 243-255.

43. In a further study, Sadler-Smith and Shefy reported beneficial outcomes in terms of heightening managers' understanding of the conditions necessary for intuitions to arise, and an enhanced awareness of the intuitive process itself and its associated outcomes, including a sense of perspective, self-confidence and inter- and intra-personal sensitivity and meta-cognition. See E. Sadler-Smith and E. Shefy, Developing intuitive awareness in management education, Academy of Management Learning and Education 6, 186-205 (2007).

44. L. F. Zhang and R. J. Sternberg, A threefold model of intellectual styles, Educational Psychology Review 17, $1-53$ (2005).

45. D. L. Dotlich, P. C. Cairo and S. H. Rhinesmith, Head, Heart and Guts: How the World's Best Companies Develop Complete Leaders, Jossey Bass, San Francisco (2006).

46. M. J. Kirton (ed.), Adaptors and Innovators: Styles of Creativity and Problem Solving, Routledge, London (1989); M. J. Kirton and R. M. McCarthy, Cognitive climate and organizations, Journal of Occupational Psychology 61, 175-184 (1988).

47. Klein (2003). See also M. M. Crossan, H. W. Lane and R. E. White, An organizational learning framework: from intuition to institution, Academy of Management Review 24, 522-537 (1999); Hodgkinson and Sparrow (2002).

48. Works supporting intuition as a precursor to creativity include T. Bastick, Intuition: How We Think and Act, Wiley, New York (1982); R. A. Finke, T. B. Ward and S. M. Smith, Creative Cognition: Theory, Research, and Applications, MIT Press, Cambridge, MA (1992). See also Claxton (1998) 217-220. Hodgkinson and Sparrow (2002). Miller and Ireland (2005) 19-30.

49. In taking this line of inquiry forward, researchers, educators and managers should heed the timely warning of Michael Gazzaniga (2006, p. 66): “The hype about neuroscience we're now seeing has happened before, with the original left brain/right brain research, which I helped pioneer. Our work got hugely distorted in the popular press, and it was impossible to find hard data for most of the claims that were being made. The failure to live up to the hype arguably obscured the real advances we did make... no one gains from a pseudoscientific approach to business, least of all managers. While I understand the appeal of bringing scientific rigour to this area of management, the quest for certainty could well devalue the intuition that managers traditionally rely on. In the end, investors pay managers to exercise good judgment, not to read scanner printouts." The key to avoiding this pitfall is through the adoption of a social cognitive neuroscience approach, which, "requires the insights from each of the social [and organizational], cognitive and neuroscience levels of analysis" (Lieberman, 2000, p. 127). As observed by Hodgkinson and Healey (2008, p. 403), this approach holds considerable promise as a basis for enriching understanding of a variety of non-conscious cognitive and affective processes in organizations, beyond intuition per se. See Hodgkinson and Healey (2008) 387-417; M. D. Lieberman, Intuition: a social cognitive neuroscience 
approach, Psychological Bulletin 127, 109-137 (2000); M. S. Gazzaniga, The brain as boondoggle, Harvard Business Review 66 (March-April 2006).

50. In 1955, Cronbach and Meehl argued that a nomological net surrounding a construct must exist if the construct is to be validated. With a fairly new construct (such as intuition) there may only be a few specifiable connections to other constructs, but as intuition research proceeds links to other constructs will become more and better established and eventually consolidated into an identifiable net of associations. See L. J. Cronbach and P. E. Meehl, Construct validity in psychological tests, Psychological Bulletin 52, 281-302 (1955).

\section{Biographies}

Gerard P. Hodgkinson is Professor of Organizational Behaviour and Strategic Management and Director of the Centre for Organizational Strategy, Learning and Change (COSLAC) at Leeds University Business School, University of Leeds. A Senior Fellow of the UK ESRC/EPSRC Advanced Institute of Management (AIM) Research, his research centres on the psychological analysis of strategy-making processes and managerial and organizational cognition. His work has appeared in a number of leading psychology and management journals including the Annual Review of Psychology, Organizational Research Methods, Organization Studies, Personnel Psychology, and Strategic Management Journal. From 1999-2006 he was the Editor-in-Chief of the British Journal of Management, and currently (with J. Kevin Ford) co-edits the International Review of Industrial and Organizational Psychology. gph@lubs.leeds.ac.uk

Eugene Sadler-Smith is Professor of Management Development and Organizational Behaviour at the University of Surrey's School of Management. His current research interests are centred upon the role of intuitive judgment in management decision making and management development. He is author of several books including Inside Intuition (Routledge, 2008) and The Intuitive Mind (John Wiley and Sons, forthcoming). His intuition research has featured on BBC Radio 4 and in The Times. e.sadler-smith@surrey.ac.uk

Lisa A. Burke is an associate professor at the University of Tennessee at Chattanooga. Lisa researches in the areas of management training, development and education. Lisa-Burke@utc.edu

Guy Claxton is Professor of the Learning Sciences and Co-Director of the Centre for Real-World Learning at the University of Winchester, UK. He is the author of the best-selling Hare Brain, Tortoise Mind: Why Intelligence Increases When You Think Less, and co-editor of The Intuitive Practitioner: On The Value of Not Always Knowing What One is Doing. Guy.Claxton@winchester.ac.uk

Paul R. Sparrow is Director, Centre for Performance-Led HRM and Professor of International Human Resource Management at Lancaster University Management School. He has published over 100 books, journal articles and chapters and consulted with major multinationals, public sector organizations and inter-governmental agencies. In 2008 he was voted amongst the Top 25 Most Influential HR Thinkers by Human Resources Magazine. His research covers cross-cultural and international HRM, HR strategy, cognition at work and changes in the employment relationship.p.sparrow@lancaster.ac.uk 